\title{
Systems of knowledge representation based on stratified graphs. Application in Natural Language Generation
}

\author{
DANiela DĂNCIULESCU ${ }^{1,2}$ and MihaEla COLHON ${ }^{2}$
}

\begin{abstract}
.
The concept of stratified graph introduces some method of knowledge representation (see [Ţăndăreanu, N., Knowledge representation by labeled stratified graphs, Proc. 8th World Multi-Conference on Systemics, Cybernetics and Informatics, 5 (2004), 345-350; Țăndăreanu, N., Proving the Existence of Labelled Stratified Graphs, An. Univ. Craiova Ser. Mat. Inform., 27 (2000), 81-92]) The inference process developed for this method uses the paths of the stratified graphs, an order between the elementary arcs of a path and some results of universal algebras. The order is defined by considering a structured path instead of a regular path. In this paper we define the concept of system of knowledge representation as a tuple of the following components: a stratified graph $\mathcal{G}$, a partial algebra $Y$ of real objects, an embedding mapping (an injective mapping that embeds the nodes of $\mathcal{G}$ into objects of $Y$ ) and a set of algorithms such that each of them can combine two objects of $Y$ to get some other object of $Y$. We define also the concept of inference process performed by a system of knowledge processing in which the interpretation of the symbolic elements is defined by means of natural language constructions. In this manner we obtained a mechanism for texts generation in a natural language (for this approach, Romanian).
\end{abstract}

\section{Acknowledgement.}

This work was supported by the strategic grant POSDRU/159/1.5/S/133255, Project ID 133255 (2014), co-financed by the European Social Fund within the Sectorial Operational Program Human Resources Development 2007-2013.

\section{REFERENCES}

[1] Akers, S. and Krishnamurthy, B., A group-theoretic model for symmetric interconnection networks, IEEE Trans. Comput., 38 (1989), No. 4, 555-566

[2] Boicescu, V., Filipoiu, A., Georgescu, G. and Rudeanu, S., Lukasiewicz-Moisil Algebra, Ann. Discrete Math., 49 (1991)

[3] Dănciulescu, D. and Colhon, M., Splitting the structured paths in stratified graphs. Application in Natural Language Generation, An. Ştiinţ. Univ. Ovidius Constanţ, Ser. Mat., vol. XXII (2), ISSN: 1224-1784, doi: 10.2478/auom-2014-0031, (2014)

[4] Karci, A., New Interconnection Networks: Fibonacci Cube and Extended Fibonacci Based Hierarchic Networks, Proc. $15^{\text {th }}$ Intl. Conf. On Information Networking, 2001, 869-876

[5] Tुăndăreanu, N., Knowledge Bases with Output, Knowl. Inf. Syst., 2 (2000), No. 4, 438-460

[6] Ţăndăreanu, N., Collaborations between distinguished representatives for labelled stratified graphs, An. Univ. Craiova Ser. Mat. Inform., 30 (2003), No. 2, 184-192

[7] Ţăndăreanu, N., Distinguished Representatives for Equivalent Labelled Stratified Graphs and Applications, Discrete Appl. Math., 144 (2004), No. 1-2, 183-208

[8] Țăndăreanu, N., Knowledge representation by labeled stratified graphs, Proc. 8th World Multi-Conference on Systemics, Cybernetics and Informatics, 5 (2004), 345-350

Received: 29.10.2014; In revised form: 01.02.2015; Accepted: 26.11.2015

2010 Mathematics Subject Classification. 05C20, 18A10, 68T30.

Key words and phrases. Peano algebra, labeled graph, stratified graph, morphism of partial algebras, structured path, accepted structured path, inference process.

Corresponding author: Dănciulescu Daniela; danadanciulescu@gmail.com 
[9] Ţăndăreanu, N. and Ghindeanu, M., Hierarchical Reasoning Based on Stratified Graphs. Application in Image Synthesis, Proc. 15th International Workshop on Database and Expert Systems Applications (DEXA2004), Zaragoza, Spania, IEEE Computer Society, Los Alamitos California, 3 (2004), 498-502

[10] Țăndăreanu, N., Proving the Existence of Labelled Stratified Graphs, An. Univ. Craiova Ser. Mat. Inform., 27 (2000), 81-92

[11] Ţăndăreanu, N. and Zamfir, C., Slices and extensions of w-trees, An. Univ. Craiova Ser. Mat. Inform., 38 (2011), No. $1,72-82$

[12] Zelina, I, Pop, P., Pop Sitar, C. and Taşcu, I., A parallel algorithm for Interpolation in Pancake Graph, in Proceedings of 6th WSEAS International Conference, Corfu, Greece, 2007, 98-101

[13] Zelina, I., Moldovan, G. and Pop, P. C., Some Communication Aspects in Extended Finobacci Cubes, IEEE Proc. of SAINT2008, Workshop HEUNET08, Turku, Finland, publisher IEEE Computer Society Press, 2008, 245-248

[14] Zelina, I., Hamiltonian paths and cycles in Fibonacci cubes, Carpathian J. Math., 24 (2008), No. 1, 149-155

[15] Zelina, I., On embedding Fibonacci meshes on Fibonacci cube networks, Carpathian J. Math., 22 (2006), No. 1-2, $173-178$

\author{
${ }^{1}$ Department of COMPUTER SCIENCE \\ THE WEST UNIVERSITY OF TIMISOARA \\ BlvD. V. PrVAn 4, Timisoara 300223, Timis, Romania \\ E-mail address: danadanciulescuegmail.com \\ ${ }^{2}$ Department of Computer SCience \\ UNIVERSITY OF CRAIOVA \\ A. I. CuZA 13, 200585 Craiova, Romania \\ E-mail address: danadanciulescuegmail.com \\ E-mail address: mcolhon@gmail.com
}

